\title{
Managing change in general practice: introduction
}

\author{
Mike Pringle
}

This is the first in a series of articles dealing with aspects of managing change in general practice
There is a popular myth, especially evident among politicians, that general practice is ultraconservative. Little has changed over the years and little will change in the foreseeable future. We are, in short, a cold bed of Luddites.

This misconception derives, I believe, from the fact that, as in all professions, new ideas are treated with healthy scepticism until their worth is evident. Once adopted by a large minority, however, innovations quickly become the norm. Politicians are uncomfortable with this. If they encourage changes they are usually experimented with, evaluated, and, finally, after some time, may be adopted. This makes change unpredictable and slow, so they often opt for a second course, imposition, which in its turn creates problems of acceptance and morale.

The reality is, as every practitioner knows, that change is endemic in general practice - it just may not happen in the way that outsiders would wish. On reflecting back over the past 10 years in our practice the evidence is stark. We have moved from an extension on the back of the then senior partner's house to a purpose built medical centre. Staffing has increased from just two dispensers to include a manager, secretary, data analyst, two practice nurses, and a cohort of receptionists and dispensers. We have seen the arrival of an internal telephone system, pagers, computers, nebulisers, electrocardiographs, defibrillators, and sonic aids. The clinical work has changed from being almost totally reactive to planned care for chronic disease and

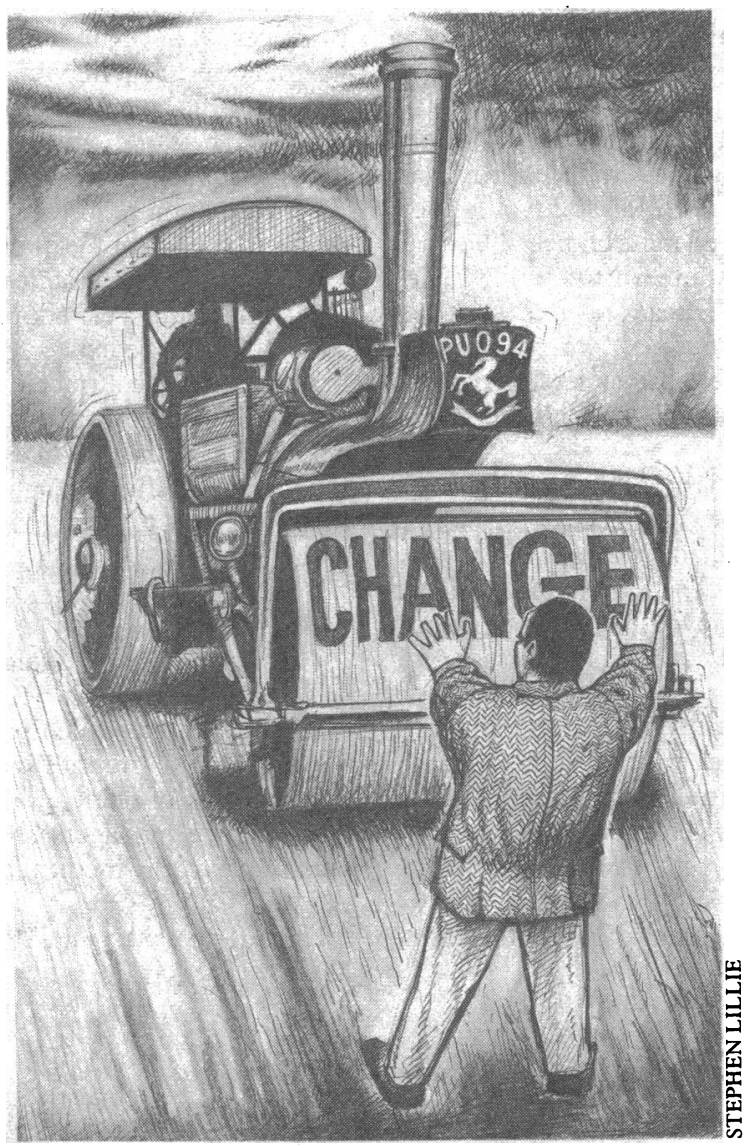

a pervasive emphasis on prevention. We now have vocational trainees and students; a patient participation group and annual reports; medical audit; and prescribing formularies.

These changes have been replicated throughout general practice, but their evolutionary nature precludes the announcement of a revolution. We need to sensitise ourselves to the degree of change that we have been involved in, and to proclaim it to the world outside.

\section{How well do general practitioners manage change?}

To many practices change is something that happens to them. It is an uncontrollable steam roller that thunders over them, always leaving destruction in its wake. This sense of passivity was clearly illustrated to me during a weekend meeting in March 1990, just a month before the new contract was imposed. There were a number of general practitioners and practice managers who had done no preparation. They had not begun to organise their preventive care to achieve the targets, or to plan for visits to elderly people. They were staring at the front wheel of the steam roller, mesmerised.

There are, however, other practices that view change as a challenge which will yield opportunities - in even the most desperate of circumstances something can be gained. These practices set out to manage the change that confronts them, not necessarily with total success, as this example illustrates.

\section{EXAMPLE 1}

Last year our long serving practice manager announced her intention of retiring. The partners had a series of meetings at which we decided to extend the management skills in the practice and to appoint someone with experience in industry. A job description was drawn up, which included many management tasks which were either new to us or traditionally the responsibility of the partners. An improved pay and holiday package was devised and agreed (on the basis of the new job definition) with the family health services authority.

A personnel officer from a major bank was recruited to teach us shortlising and interviewing skills. In the interviews each partner had a set of predetermined and standardised questions designed to explore attitudes, skills, and knowledge. The result was substantially more satisfying and successful than any previous appointment process, and an excellent candidate was appointed.

We then discovered that our outgoing practice manager was feeling hurt and betrayed. Not only had we seemed to relish the task of appointing her successor, betraying no evidence of her indispensability, but we were offering better pay and conditions. She felt that all her years of service were being undervalued. Nottinghamshire NG23 7HJ Mike Pringle, general practitioner
Virtually any problem can be turned into an opportunity. By thinking about the process of change, the change can be managed so that the chances of a good result are increased. The partnership shared 
common objectives and acknowledged, and rectified, deficiencies in its skills. We let ourselves down, however, in communication skills and understanding. The outgoing practice manager should have been encouraged to share in the upgrading of her post, preferably by being made to feel that it was her idea, and the partners should have been more sensitive to her self esteem.

\section{Can general practitioners learn how to manage change?}

A medical degree appears to confer on a person a God given ability to manage. Within a few years the doctor is a partner in a practice with a turnover of hundreds of thousands of pounds, or perhaps a consultant in an independent hospital trust responsible for a substantial budget. While it is often accepted that skills in personnel, budgeting and finance, and project management are necessary and can be acquired, they are seldom taught. The management of change is usually totally ignored.

Many changes, especially in the past few years, are imposed from outside the practice or by unavoidable circumstances within it-such as the retirement of the manager - and the task is to minimise the disruption while maximising the benefit. Equally, many changes come voluntarily from within the practice-for example, computerisation, upgrading of premises, and vocational training. The task remains the same but the circumstances differ. The partners and practice manager are often now "imposing" the change on the practice and need to be sensitive to issues of presentation, timing, and communication.

Industry and commerce have been aware of this for many years. There are lots of lessons that are transferable to medicine, and particularly to primary care. Some of these skills, or their absence, are illustrated in this second example.

\section{EXAMPLE 2}

Last year it became apparent that our computer system needed replacing. In the autumn the new system was delivered and the partners envisaged a steady changeover, with the two computers running in parallel for some time. The system offered the facility, new to us, of prescribing in the consultation, so the partners began to use it with considerable enthusiasm.

The dispensary staff were told about the new computer but were not involved in its choice. They had minimal training, but initially all went smoothly. They found using one system for repeat and one for acute prescribing difficult, but they coped remarkably well. As the repeat prescriptions were transferred to the new system they had added difficulties through the transition but still did not complain.

It then became apparent that the new system's prescription queue for dispensing did not function correctly. Patients were ordering drugs, which were entered on the queue, but if they went too near the bottom that was where they stayed. When the patients came for their drugs they had not been dispensed. Our dispensers took all the flak for a teething problem in a computer system they had not chosen and towards which they felt no loyalty. The resulting crisis required considerable time before solutions were found and the staff felt happier with the new system.

\section{Discussion}

The partners owned the new computer both

\section{Points to note}

- Change is endemic in general practice

- The need for change can be turned into an opportunity

- Change may be imposed from outside or come from within the practice

- Appropriate management of change increases the chance of a good result

- All members of a practice should be involved in the management of change

- The appointment of a practice manager should reduce the partners' responsibility for managing change

financially and emotionally. This was not important so long as the introduction was relatively smooth, but once problems occurred the lack of staff commitment to the project was exposed. Goodwill alone is not sufficient, people need to feel an emotional investment in the success of an innovation. If the staff had taken a greater part in making the decisions on the choice of computer and its introduction then the trauma and the extra hours resolving the crisis would have been avoided.

\section{Who should do the managing?}

There is an evident transition occurring between administration and management in general practice. The old model of internal promotion of a senior receptionist to take on administrative responsibility with the misnomer of "practice manager" is giving way to the appointment of people, often from outside the health service, with management skills. This was illustrated in the first example given above.

This is not to say that partners will or should surrender their responsibilities for the future of their practices. The evolving model is one in which the partners and practice manager decide broad strategy (for example, whether premises should be extended) but the practice manager supervises the process, reporting back to the practice meeting on progress. This delegation requires skills of a high order from the partners if it is not to become an abdication.

And the new practice managers, who may be receiving profit related pay, will require high level skills to fulfil the expectations of the partners and the practice. As our contract, our task, and our bureaucratic relationships become more complex so does the job description of the practice manager, but the basic skills for the successful management of change will remain the same.

\section{Conclusion}

Change cannot be avoided but it can be managed. This does not mean it becomes painless, but the pain can be mitigated while the benefits are maximised. All members of a practice need to be involved in this management of change, although the appointment of real practice managers should reduce the direct responsibility of the medical partners.

This series has been edited by $\operatorname{Dr} M$ Pringle. 